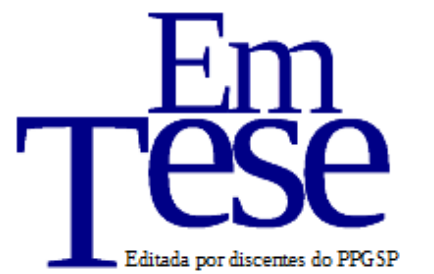

\title{
Os impactos da presença da sociologia nos sistemas de ingresso ao ensino superior: o que dizem os professores
}

\author{
Alexandre Barbosa Fraga ${ }^{1}$ \\ Thiago Oliveira Lima Matiolli
}

\section{Introdução}

É possível constatar, recentemente, o reconhecimento da participação da Sociologia nos sistemas de avaliação externos à escola. No ENEM, por exemplo, está presente oficialmente desde 2009. Nos vestibulares, em geral, sua participação foi sendo ampliada ao longo dos anos 2000 e se mantém até hoje. Em pesquisas que realizamos anteriormente nesse mesmo tema, estudamos as formas pelas quais a Sociologia vem sendo cobrada nessas provas e os conteúdos presentes nelas. Neste trabalho especificamente, analisaremos se o imaginário que foi produzido sobre a presença da Sociologia nesses exames vem, e em que nível, influenciando a prática cotidiana das aulas dessa disciplina, no sentido de acabar modificando a maneira como é ensinada.

No primeiro ponto, explicitaremos as três etapas da agenda de pesquisa que estamos seguindo a respeito da participação da Sociologia nos sistemas de avaliação, representando este trabalho a terceira delas. Na parte seguinte, defenderemos que, desde a obrigatoriedade, a Sociologia vem percorrendo um caminho em busca de legitimidade que a faz passar por alguns enquadramentos, como, por exemplo, ser cobrada nos

\footnotetext{
${ }^{1}$ Doutorando em Sociologia pelo Programa de Pós-Graduação em Sociologia e Antropologia da UFRJ. Mestre em Sociologia pelo mesmo Programa. Bacharel e licenciado em Ciências Sociais pelo IFCS/UFRJ. Com Anita Handfas e Julia Polessa Maçaira, organizou o livro Conhecimento Escolar e Ensino de Sociologia: instituições, práticas e percepções. Rio de Janeiro: 7 Letras, 2015. E-mail: alexbfraga@yahoo.com.br.

${ }^{2}$ Doutorando em Sociologia pelo Programa de Pós-Graduação em Sociologia da USP. Mestre em Planejamento Urbano e Regional pelo Programa de Pós-Graduação do Instituto de Pesquisa e Planejamento Urbano e Regional da UFRJ. Bacharel em Ciências Sociais pelo IFCS/UFRJ. Autor do livro Metáforas da Cidade Partida: a divisão territorial do Rio de Janeiro nas eleições municipais de 2008. Rio de Janeiro: Multifoco, 2013. E-mail: thiagoolmatiolli@gmail.com.
} 
exames externos à escola. Enquadramento esse que cria um imaginário sobre a presença dessa disciplina no ENEM, o qual não corresponde em todo à realidade. No último ponto, buscaremos compreender se esse imaginário produz efeitos concretos na prática cotidiana das salas de aula de Sociologia da educação básica, alterando a dinâmica pela qual ela é ensinada. Isso será feito por meio da análise das entrevistas com professores de Sociologia da rede pública e privada do Rio de Janeiro.

\section{Sociologia e avaliações: etapas de uma agenda de pesquisa}

O crescimento da produção acadêmica sobre o ensino de Sociologia na educação básica, sobretudo a partir dos anos 2000, é visível e pode ser percebido nos mais diferentes formatos: artigos em periódicos, trabalhos apresentados em eventos científicos, livros, dissertações e teses. Nos levantamentos que buscaram de alguma forma mapear essa produção científica (HANDFAS; MAÇAIRA, 2012; CAREGNATO; CORDEIRO, 2014), fica claro que algumas temáticas acabaram, pelo menos por enquanto, ganhando uma maior projeção, isto é, sendo mais pesquisadas e, portanto, compreendidas de maneira mais sistemática ${ }^{3}$.

Devido a esses primeiros mapeamentos bibliográficos, tornou-se possível também, em contraponto, observar as lacunas dessa produção e as temáticas ainda não muito investigadas. É neste grupo que deve ser incluído o tema da presença da Sociologia nos sistemas de avaliação, sobretudo externos à escola, como o ENEM e os vestibulares. Esse objeto de estudo tem nos interessado há algum tempo e nos mobilizado a produzir algumas reflexões a partir de dados empíricos coletados.

Essas reflexões podem ser percebidas - e assim mais facilmente compreendidas - como etapas de uma agenda de pesquisa sobre a participação da Sociologia nos sistemas de avaliação. Na primeira etapa (FRAGA; MATIOLLI, 2012 e 2013), analisamos as formas pelas quais a Sociologia vem sendo cobrada nas provas dos vestibulares de pelo menos dezesseis universidades públicas em diferentes regiões brasileiras ao longo dos anos 2000; e no ENEM, no qual está presente oficialmente

\footnotetext{
${ }^{3}$ No levantamento realizado por Handfas e Maçaira (2012), por exemplo, com base no banco de teses da Capes, em que foram analisadas as dissertações de mestrado e teses de doutorado defendidas em programas de pós-graduação entre 1993 e 2012, seis grandes temas apareceram: currículo; práticas pedagógicas e metodologias de ensino; concepções sobre a sociologia escolar; institucionalização das ciências sociais; trabalho docente; e formação do professor.
} 
desde 2009, na prova de Ciências Humanas e suas Tecnologias ${ }^{4}$. Acreditávamos que esse enquadramento, de alguma forma, alterava o grau de liberdade e de legitimidade dessa disciplina na educação básica.

Analisando o conjunto de provas elaborado por essas universidades e pelo Instituto Nacional de Estudos e Pesquisas Educacionais (INEP), foi possível perceber que a participação da Sociologia no vestibular e no ENEM se dá, respectivamente, de três e de quatro maneiras específicas. No caso do vestibular, são estes os caminhos: $1^{\circ}$ ) dialogando principalmente com a História, a Geografia e a Filosofia, de maneira interdisciplinar; $2^{\circ}$ ) exigindo que os candidatos dominem conceitos e teorias pela interpretação de pensadores específicos da área; $3^{\circ}$ ) demandando conhecimento do pensamento sociológico geral sobre determinados temas, sem que para isso seja preciso identificar autores.

No caso do ENEM, a Sociologia marca presença de quatro formas distintas e simultâneas: $1^{\mathrm{a}}$ ) indiretamente, na interface com a redação ${ }^{5} ; 2^{\mathrm{a}}$ ) como pano de fundo, contextualizando questões das outras disciplinas de Ciências Humanas; $3^{\mathrm{a}}$ ) de maneira interdisciplinar, quando a resolução de uma questão depende da interseção entre a Sociologia e, pelo menos, mais uma disciplina; $4^{\mathrm{a}}$ ) em questões que apresentam um texto de cunho sociológico a ser interpretado, isto é, não há cobrança sobre o aluno do que chamamos de conhecimento prévio da matéria para sua resolução.

$\mathrm{Na}$ segunda etapa dessa agenda de pesquisa (FRAGA; MATIOLLI, 2014a), a partir das conclusões da etapa anterior, sobretudo no que tange à quarta forma de cobrança da matéria no ENEM, passamos a refletir sobre o que é o conhecimento prévio cobrado nas provas - ou elemento decisivo, como chamado por Cerri (2004) nas questões de história do ENEM que analisou -, ou seja, aquilo que cada disciplina ensina como parte do conjunto de conhecimentos que lhe são próprios. No caso específico da Sociologia, pode ser entendido como conceitos, temas e teorias sociológicas ${ }^{6}$. Para isso, analisamos quais são, segundo os editais das universidades, as matérias de Sociologia

\footnotetext{
${ }^{4}$ No ENEM, portanto, a prova está estruturada por áreas de conhecimento, embora a escola esteja organizada disciplinarmente. Nas duas primeiras etapas da pesquisa (FRAGA; MATIOLLI 2012 e 2014a), refletimos sobre isso, analisando a interdisciplinaridade, sua relação com sistemas de avaliação e o papel da Sociologia.

${ }^{5}$ Para uma análise especificamente das contribuições da Sociologia para a redação do ENEM, ver Fraga e Matiolli (2015).

${ }^{6}$ Conforme sugerido nas Orientações Curriculares Nacionais para o Ensino Médio. Ver Moraes, Tomazi e Guimarães (2006).
} 
presentes em alguns vestibulares e vimos que é possível chegar a um mapa comum compatível com os currículos mínimos estaduais.

$\mathrm{O}$ presente artigo corresponde à terceira etapa dessa agenda de pesquisa e teve uma versão inicial apresentada no $4^{\circ}$ Encontro Estadual de Ensino de Sociologia do Rio de Janeiro (FRAGA; MATIOLLI, 2014b). Nele, queremos discutir os efeitos concretos da presença da Sociologia nesses exames para o currículo de Sociologia no Ensino Médio e para a prática cotidiana de sala de aula. Sendo assim, entrevistamos alguns professores que lecionam Sociologia na educação básica, antes e depois da sua obrigatoriedade em todas as séries do ensino médio, Lei $n^{\circ} .11 .684$ de 2008, para perceber se e como essa sua maior presença nesses exames nos últimos anos - ou pelo menos a construção de um imaginário sobre a sua participação mais efetiva neles alterou a maneira como os professores vêm ensinando-a em suas práticas cotidianas.

\section{O enquadramento se acentua: a construção de um imaginário sobre a cobrança da sociologia nas avaliações externas à escola}

Desde o retorno obrigatório da Sociologia à educação básica, um caminho vem sendo percorrido em prol de sua legitimação para além da lei. Caminho esse que pode ser percebido como uma troca de liberdade por legitimidade, através de um enquadramento (FRAGA; MATIOLLI, 2012). Se antes a liberdade na escolha dos conteúdos, do aporte teórico e metodológico e dos caminhos para se ensinar Sociologia era maior, ou mesmo estava totalmente em aberto, isso vem sendo alterado nos últimos anos, quando vão se consolidando enquadramentos, isto é, maneiras consideradas mais legítimas do que outras de a Sociologia ser pensada e ensinada.

Entre esses enquadramentos que, no geral, passam a sugerir ou mesmo a indicar o que a Sociologia deve ensinar e como, podemos citar a elaboração de documentos oficiais, como PCNs e OCNs; a divulgação de diretrizes curriculares estaduais, definindo os conteúdos a estarem presentes nas aulas; a aprovação de determinados livros no Programa Nacional do Livro Didático (PNLD), edições de 2012 e 2015 (MEC, 2011 e 2014); e a cobrança da Sociologia em alguns vestibulares e no ENEM, de alguma maneira impondo conteúdos e formas de ensino à educação básica. 
O último desses enquadramentos acaba construindo um imaginário sobre a cobrança da Sociologia nas avaliações externas à escola, que, muitas vezes, não corresponde tanto à realidade, sobretudo quando se trata do ENEM. Embora, então, na prática, a Sociologia ainda se apresente nesse exame de maneira tênue, há um imaginário que, de alguma forma, enxerga essa participação como algo muito mais sólido, como pode ser percebido todos os anos quando os meios de comunicação, sobretudo portais da internet, vão corrigir a prova. Os professores chamados a comentar a parte de humanas acabam expandindo uma percepção de que a Sociologia estaria ganhando projeção no exame, sendo demandados cada vez mais intensamente seus conhecimentos específicos.

Esse imaginário, embora não corresponda exatamente à realidade, acaba produzindo efeitos sobre ela, os quais, por sua vez, reforçam-no, em um dispositivo que se retroalimenta. Isso pode ser percebido no discurso dos alunos, dos professores, em publicações que tentam atingir um público mais amplo, nos livros aprovados pelo PNLD e, como veremos no próximo ponto, na prática de sala de aula. Nesse sentido, observamos, por exemplo, alunos de um pré-vestibular da cidade do Rio de Janeiro reclamarem da não existência de aulas de Sociologia e Filosofia, o que, segundo eles, atrapalharia a preparação para a prova do ENEM, diminuindo as chances de eles ingressarem na universidade. Essa participação "ativa" da Sociologia no ENEM também acaba sendo muito enfatizada por professores, querendo, com isso, legitimar a Sociologia e igualá-la - mesmo que de maneira utilitária - às demais disciplinas.

Além disso, nas bancas de jornal, passou a ser vendida no ano de 2014 uma publicação chamada Almanaque de Sociologia para vestibular e ENEM, da Editora OnLine. Foram produzidos cinco volumes: Mundo do trabalho; Política, Estado e poder; Introdução e conceitos básicos; Movimentos sociais; e Cultura e comunicação. Na capa desses almanaques, há frases como: "aprenda os temas de Sociologia cobrados no ENEM e vestibular", "gabarite a prova", "Sociologia explicada para passar nos exames mais concorridos do país" e "professor explica e dá dicas sobre a matéria". Essas publicações realimentam a ideia de que não apenas a Sociologia está presente no ENEM, como também pode ser colocada em igualdade com as outras disciplinas no que diz respeito às estratégias de preparação para a prova. 
A quase totalidade dos livros indicados pelo Programa Nacional do Livro Didático (PNLD, 2015), por sua vez, também apresentou alguma preocupação com essa questão. Foram seis os livros aprovados, listados em ordem alfabética de seus autores: Sociologia (ARAÚJO; BRIDI; MOTIM, 2013), Tempos modernos, tempos de Sociologia (BOMENY; FREIRE-MEDEIROS; EMERIQUE et al, 2013), Sociologia hoje (MACHADO; AMORIM; BARROS, 2013), Sociologia para jovens do século XXI (OLIVEIRA; COSTA, 2013), Sociologia em movimento (SILVA; LOUREIRO; MIRANDA et al, 2013) e Sociologia para o ensino médio (TOMAZI, 2013).

A análise do conteúdo desses seis livros didáticos nos permite dividi-los em três grupos, no que diz respeito à preocupação com sistemas de avaliação externos à escola, como vestibulares e ENEM: despreocupados (TOMAZI, 2013), pouco preocupados (ARAÚJO; BRIDI; MOTIM, 2013 e MACHADO; AMORIM; BARROS, 2013) e muito preocupados (BOMENY; FREIRE-MEDEIROS; EMERIQUE et al, 2013; OLIVEIRA; COSTA, 2013; e SILVA; LOUREIRO; MIRANDA et al, 2013). Em todos os casos, foram analisadas as versões produzidas para uso do professor. Assim, tornouse possível observar tanto o material voltado aos estudantes (livro do aluno) quanto as orientações direcionadas aos docentes (manual do professor).

Em relação ao primeiro grupo, no qual está inserido apenas o livro Sociologia para o ensino médio (2013), de autoria de Nelson Dacio Tomazi, publicado pela Saraiva, tanto na parte do aluno quanto na do professor não há nenhuma referência a avaliações externas, voltadas à inserção no ensino superior.

No que diz respeito ao segundo grupo, em que há pouca preocupação, a primeira obra que faz parte dele é Sociologia (2013), de autoria de Silvia Araújo, Maria Bridi e Benilde Motim, publicado pela Scipione. Ao final do livro do aluno, há quatro páginas em que são listadas 18 questões do ENEM, dos anos 2010, 2011 e 2012, ordenadas conforme a apresentação dos conteúdos na obra. Já a leitura do manual do professor revelou não haver uma discussão sobre o assunto, apenas a indicação do gabarito das questões do ENEM citadas. O segundo livro deste grupo é Sociologia hoje (2013), da editora Ática, cujos autores são Igor Machado, Henrique Amorim e Celso Barros. Não são incluídas questões de exames externos, mas, no manual do professor, na parte que reflete sobre a avaliação, está escrito que a avaliação das habilidades e competências também pode ser referenciada nos eixos cognitivos comuns a todas as áreas do 
conhecimento propostos pelo ENEM, citados pelos autores. Quanto à Matriz de humanas do ENEM, o manual indica o endereço eletrônico em que ela pode ser baixada e sugere ao professor: "Avalie detalhadamente a Matriz de Referência de Ciências Humanas e suas Tecnologias procurando destacar as especificidades e as contribuições das Ciências Sociais e desta obra na consecução dos objetivos pedagógicos" (p. 336).

Por fim, o terceiro grupo é formado por três livros considerados por nós muito preocupados com as avaliações externas à escola. Por exemplo, em Tempos modernos, tempos de Sociologia (2013), da Editora do Brasil, de autoria de Helena Bomeny, Bianca Freire-Medeiros, Raquel Emerique et al, ao final de cada capítulo há uma parte chamada "De olho no ENEM", que apresenta uma ou mais questões desse exame. No manual do professor, essa seção é assim explicada:

\begin{abstract}
Abrangemos o Enem entre 1998 e 2012, com até cinco questões por capítulo. Aqui, temos a oportunidade de explorar a multi e a interdisciplinaridade dos temas estudados, certos de que o domínio de várias linguagens científicas ajudará o estudante a compreender de forma mais ampla um problema ou questão social (p. 12-13).
\end{abstract}

É preciso registrar também que há a preocupação de comentar essas questões na parte direcionada ao professor.

O livro Sociologia para jovens do século XXI (2013), por sua vez, publicado pela editora Imperial Novo Milênio, e escrito por Luiz Oliveira e Ricardo Costa, por meio da seção "Verificando o seu conhecimento", inclui, assim como o anterior, questões do ENEM em todos os seus capítulos. O manual do professor explica essa seção da seguinte maneira: “(...) nos preocupamos em fazer um apanhado de questões, relacionadas a temas e conceitos das Ciências Sociais, presentes naquele que vem se transformando, ao longo dos últimos anos, no principal processo de avaliação nacional para o acesso ao ensino superior - o ENEM" (p. 418).

Já no livro de Afrânio Silva, Bruno Loureiro, Cassia Miranda et al, Sociologia em movimento (2013), editado pela Moderna, a parte "Atividades", ao final de cada capítulo, contém questões ora do ENEM, ora de vestibulares, ora de ambos, que são comentadas no manual do professor, onde essa seção é assim explicada:

As questões de múltipla escolha exigem habilidades específicas para a sua resolução e, mais do que ser um mero exercício de "acerto" e "erro" é importante que o estudante possa identificar os diferentes processos (habilidades necessárias e domínios cognitivos específicos) em que encontra 
maior ou menor facilidade para que possa, junto ao docente, desenvolver estratégias para atingir uma proficiência satisfatória nas competências em que encontra dificuldade (Idem, p. 9).

Estes diferentes exemplos, a saber, a percepção dos meios de comunicação, o discurso dos alunos e dos professores, determinadas publicações que vêm surgindo e os livros aprovados pelo PNLD 2015, demonstram a existência de um imaginário que coloca peso na presença da Sociologia no ENEM, o qual, mesmo não correspondendo, pelo menos ainda, totalmente à realidade, tem impactos concretos na forma como ela é vivenciada. Como, por exemplo, a inserção da Sociologia no mercado editorial e em seus mecanismos de produção. Sendo assim, a questão que precisa ser esclarecida é que efeitos concretos são produzidos por esse imaginário na prática cotidiana das salas de aula de Sociologia da educação básica; ou ainda em que medida a dinâmica pela qual essa disciplina é ensinada acaba sendo alterada.

\section{Na prática cotidiana da sala de aula: a influência das avaliações externas à escola nas aulas de sociologia}

\subsection{A construção do imaginário: comparação temporal}

Dando continuidade à reflexão, a realização de entrevistas com professores de Sociologia da educação básica permitiria captar os efeitos do ENEM, ou do imaginário sobre a presença da Sociologia nesse exame, no ensino dessa disciplina. Mas a seguinte questão metodológica se colocou: qual escola escolher para fazer a pesquisa? Ou deveríamos comparar escolas? Resolvemos começar nosso estudo pelo Colégio Pedro II, localizado na cidade do Rio de Janeiro, entrevistando Fatima de Oliveira, professora de Sociologia dessa instituição, de 1994 a 2007; chefe de departamento, de 2007 a 2013; e atualmente diretora de pesquisa. Fatima se revelou uma boa escolha, pois, além de ter sido professora de Sociologia, também assumiu o cargo de chefe de departamento, o que a deixava informada, de alguma forma, sobre o trabalho dos demais professores e sobre as discussões travadas no espaço escolar.

O problema é que o impacto curricular dos sistemas de avaliação externos vai ser sentido de maneira diferente de acordo com o lugar de trabalho do professor: na rede privada ou pública; na rede estadual ou federal; e, ainda, dentro de cada uma dessas 
redes de acordo com a escola em que se lecione. Como comparar os efeitos dessas avaliações sobre o ensino sem que outras variáveis interfiram? A decisão pelo Colégio Pedro II foi, portanto, metodológica. Se o que se quer mapear são os impactos da presença da Sociologia nos sistemas de avaliação sobre a prática cotidiana docente, a melhor estratégia encontrada foi dar os primeiros passos a partir da reconstrução de uma trajetória histórica.

Para deixar em suspenso os problemas metodológicos acima apontados, o melhor seria comparar, em uma mesma escola, a forma como a Sociologia é ensinada antes e depois da existência de um imaginário sobre a sua presença no ENEM. Pareceunos que essa perspectiva histórica, de ver as transformações na prática docente ao longo do tempo, seria muito útil para dar prosseguimento à pesquisa. O Colégio Pedro II nos permitiria tal análise, já que, por contar há anos com a disciplina, poderia ser um bom lugar para acompanhar essa passagem temporal.

Tendo sido escolhida a escola pela qual começar a pesquisa, é interessante destacar o perfil de Fatima $^{7}$, nossa primeira entrevistada, com sua experiência de mais de vinte anos como professora de Sociologia e sete como chefe de departamento do Colégio Pedro II. Apresentaremos, a seguir, os elementos que mais nos interessaram durante a entrevista, quais sejam: as tensões entre a formação para a cidadania e a preparação para o ingresso no ensino superior, ambas presentes no Colégio antes e depois da obrigatoriedade da Sociologia na educação básica, bem como antes e depois de essa disciplina ser cobrada nos vestibulares e no ENEM; as divergências que surgiram em torno da utilização do modelo ENEM na preparação das aulas; e os efeitos da presença da Sociologia nessas provas em relação à escolha de temas e de questões para serem inseridas no trabalho cotidiano dessa disciplina.

$\mathrm{Na}$ fala de Fatima, parece haver uma grande preocupação em articular o ensino de Sociologia à formação dos alunos para o exercício da cidadania, havendo em paralelo uma necessidade de prepará-los para o ingresso na universidade. Ela conta que os alunos do Colégio têm perfis diversos: há aqueles que querem a entrada no ensino superior, outros que vão trabalhar logo ao final do ensino médio ou ainda os que vão tentar concursos públicos. Isso redimensiona um pouco a ênfase na preparação dos

\footnotetext{
7 Trabalhou na rede estadual e no Colégio Pedro II; no ensino médio, fundamental, infantil e superior; nas modalidades de EJA e PROEJA, na formação de professores secundaristas.
} 
alunos para o ingresso no ensino superior. Ela não é suprimida, mas não monopoliza a prática docente no ensino médio.

Essa preocupação com a preparação para avaliações externas não é nova no Colégio, já existia na década de 1990, então para os vestibulares. Nesse sentido, também se colocava para os professores de Sociologia a questão de como preparar para o vestibular, ao mesmo tempo em que isso sempre foi uma forma de legitimar o ensino da disciplina para os alunos. Isso significa que essa preparação específica estava presente nos dois momentos, ainda que, obviamente, com a obrigatoriedade e a inclusão no ENEM, essa discussão amplie seu escopo. A questão da preparação para o ingresso no ensino superior complexifica o debate sobre o papel da disciplina de Sociologia no ensino médio: entre formação para a cidadania, o ensino do conteúdo em si e a preparação para o ingresso no nível superior.

Nas respostas da Fatima, fica claro que os efeitos desse debate na prática docente cotidiana, na preparação de aulas e provas, não são homogêneos, mas diversos. Como o Colégio Pedro II é uma rede, essas tensões se manifestam de uma unidade para outra. Isto é, a forma como o ENEM impacta a preparação das aulas é variada entre as unidades. Assim, por exemplo, Fatima cita o caso de uma unidade em que a aplicação de simulados foi questionada. Aparentemente, em um primeiro momento, os professores de Sociologia teriam se recusado a contribuir com questões para o simulado e, em um momento posterior, a unidade em si teria rechaçado a dinâmica dos simulados. Já em outra, essa dinâmica foi aceita, inclusive com a inserção de questões de Sociologia.

Por fim, outro aspecto é o da influência das avaliações externas à escola na preparação de aulas e avaliações internas. Segundo Fatima, há a utilização de questões do ENEM e de vestibulares nas provas, sendo mais um recurso possível de preparação das atividades, e não o grande eixo que a orienta. Ou seja, uma questão do ENEM ou de um vestibular, por exemplo, às vezes é incluída nas provas de Sociologia da escola, mas apenas se, na avaliação dos professores, corresponder aos objetivos daquele bimestre, e não simplesmente por ter feito parte da prova de um concurso. E, como o Colégio Pedro II tem um espaço de discussão constante sobre o conteúdo das aulas, professores já sugeriram a abordagem de determinados temas que estariam frequentemente aparecendo no ENEM. No entanto, novamente, estar sendo cobrado nesse exame era apenas mais um argumento para convencer a equipe da importância do tema, mas a ideia 
predominante era a de que, antes de tudo, estava sendo defendida essa temática pelo interesse demonstrado pelos alunos em discuti-la.

Portanto, o que pôde ser percebido na entrevista com Fatima foram as seguintes nuances da relação entre a prática cotidiana das aulas de Sociologia e os impactos dos sistemas de avaliação e ingresso ao nível superior: a discussão sobre o papel da Sociologia na preparação para avaliações externas não é nova na escola, estando presente, embora com diferenças, nos dois momentos: antes da existência desse imaginário sobre a presença da Sociologia no ENEM (anos 90) e depois da sua construção (anos 2000); os efeitos das avaliações externas à escola não são homogêneos na prática docente, antes de tudo criam tensões e divergências, que recolocam a discussão do papel da Sociologia na educação básica; e, por fim, há a utilização de questões do ENEM e de vestibulares nas provas, e a sugestão de alguns professores para que determinados temas presentes em exames anteriores sejam incorporados às aulas, desde que eles contribuam para a formação mais geral do aluno esperada pelo corpo docente do Colégio, para além de apenas aumentarem as chances de entrada na universidade.

\subsection{Momento presente: efeitos concretos do imaginário}

Na primeira entrevista, buscamos fazer uma reflexão de cunho mais histórico, resgatar as percepções de uma professora sobre dois momentos distintos: antes e depois da obrigatoriedade da presença da Sociologia nas provas externas à escola. Como continuidade da reflexão, pareceu-nos frutífero entrevistar professores/as que, embora não possam comparar períodos diferentes, já que começaram a lecionar entre $2002 \mathrm{e}$ 2013, sejam capazes de refletir sobre o momento presente, buscando analisar os possíveis impactos que a presença da disciplina no ENEM teve sobre a prática docente deles.

Entrevistamos seis docentes da cidade do Rio de Janeiro: um professor da rede estadual de ensino; um professor da rede privada; duas professoras que lecionam em ambas as redes; uma professora e um professor do Colégio Pedro II $^{8}$. Cada entrevista

\footnotetext{
${ }^{8}$ Apenas o Colégio Pedro II será identificado, pois a ocultação de seu nome seria apenas mera formalidade, uma vez que qualquer leitor que dedicasse um pouco mais de atenção perceberia de qual instituição estamos falando.
} 
teve a duração de uma a duas horas. Os/as entrevistados/as foram selecionados por meio da metodologia "bola de neve", por meio da qual um entrevistado indicou outro, formando-se uma rede. Eles responderam a um roteiro com trinta e seis perguntas, dividido em três partes: Bloco 1: Dados pessoais; Bloco 2: A Sociologia no ENEM e nos vestibulares; Bloco 3: A influência das avaliações externas nas aulas e nas práticas pedagógicas. O objetivo nunca foi comparar a realidade pública estadual, federal e privada. Antes de tudo, a diversidade de experiências retratadas pelos/as entrevistados/as permite deslindar diferentes possibilidades através das quais aquele imaginário impacta o trabalho dos/as professores/as de Sociologia do ensino médio.

Com relação ao ensino privado, os/as professores/as entrevistados lecionam ao todo em três escolas diferentes: a rede de ensino que chamaremos de A, com unidades espalhadas pela cidade (na Zona Sul, Norte, Oeste e também em Niterói); a rede de ensino B, com unidades também espalhadas pelas Zonas Norte e Oeste; e, ainda, uma escola católica na Zona Norte da cidade do Rio de Janeiro. Com relação às públicas, as escolas da rede estadual em que os/as entrevistados/as trabalham estão distribuídas por Copacabana, Zona Sul; Vila Isabel, Zona Norte; e uma em Brás de Pina, Zona Norte também. Há ainda o Pedro II, da rede pública federal ${ }^{9}$.

Tabela 01: Escolas em que os/as professores/as entrevistados/as lecionam ${ }^{10}$

\begin{tabular}{|c|c|c|c|c|c|c|}
\hline \multirow[b]{2}{*}{$\begin{array}{c}\text { Professor/a e } \\
\text { idade }\end{array}$} & \multirow{2}{*}{$\begin{array}{l}\text { Ano em que } \\
\text { começou a } \\
\text { lecionar } \\
\text { Sociologia }\end{array}$} & \multicolumn{3}{|c|}{ Rede privada } & \multicolumn{2}{|c|}{ Rede pública } \\
\hline & & $\begin{array}{l}\text { Rede de } \\
\text { ensino A }\end{array}$ & $\begin{array}{l}\text { Rede de } \\
\text { ensino B }\end{array}$ & $\begin{array}{l}\text { Colégio } \\
\text { Católico }\end{array}$ & Estadual & $\begin{array}{l}\text { Colégio } \\
\text { Pedro II }\end{array}$ \\
\hline $\begin{array}{c}\text { Agostinho } \\
(30 \text { anos }) \\
\end{array}$ & 2013 & & & & $\mathrm{X}$ & \\
\hline $\begin{array}{c}\text { Bento } \\
\text { (38 anos) }\end{array}$ & 2002 & & & & & $\mathrm{X}$ \\
\hline $\begin{array}{c}\text { Ignácio } \\
\text { (31 anos) }\end{array}$ & 2009 & & $\mathrm{X}$ & & & \\
\hline $\begin{array}{c}\text { Maria } \\
\text { (30 anos) }\end{array}$ & 2011 & $\mathrm{X}$ & & $\mathrm{X}$ & $\mathrm{X}$ & \\
\hline $\begin{array}{c}\text { Mônica } \\
\text { (32 anos) }\end{array}$ & 2008 & $\mathrm{X}$ & & & $\mathrm{X}$ & \\
\hline $\begin{array}{c}\text { Rosa } \\
\text { (28 anos) }\end{array}$ & 2013 & & & & & $\mathrm{X}$ \\
\hline
\end{tabular}

9 Em que pese reconheçamos os impactos da distribuição espacial das escolas pela cidade na dinâmica escolar (ou no perfil dos alunos), não consideraremos, para fins deste trabalho, essa variável geográfica, por limites de texto. Além disso, não surgiram, nas entrevistas, grandes elementos que justificassem, nesse momento, uma atenção maior às modulações de suas práticas dentro da mesma rede de ensino, segundo a localização da unidade.

$10 \quad$ Na tabela elaborada pelos autores, os nomes dos professores são fictícios, mas o sexo, a idade e o ano em que começaram a lecionar correspondem corretamente às informações obtidas nas entrevistas. 
Quanto à formação inicial, todos os professores entrevistados fizeram graduação em Ciências Sociais em universidades públicas, cursando nelas tanto o bacharelado quanto a licenciatura. Dando continuidade aos estudos, dois deles têm mestrado na área e são doutorandos em Sociologia (Agostinho e Ignácio), três são mestres em Sociologia ou Ciências Sociais (Bento, Maria e Rosa) e um fez especialização em Gestão Ambiental (Mônica).

Realizada essa caracterização geral, após a análise das entrevistas, os seguintes aspectos despertaram interesse: a percepção da Sociologia no ensino médio no que chamaremos de vida escolar "ordinária" e "extraordinária"; e o espaço possível que o/a professor/a tem, em sala de aula, para conciliar as demandas da escola com sua própria percepção dos objetivos da Sociologia como disciplina na educação básica.

\section{a) A vida escolar ordinária e extraordinária}

O que estamos entendendo como vida escolar "ordinária" e "extraordinária" se aplica à reflexão que queremos fazer sobre os impactos da presença da Sociologia nos sistemas de ingresso ao ensino superior. Chamamos de "ordinária" o enquadramento da disciplina no "formato ENEM/Vestibular" através do material escolar, presença na grade curricular, na divisão das turmas e nos sistemas de avaliação próprios da escola; e de "extraordinária" os projetos especiais (vestibulares e ENEM) e os simulados. O que chamou nossa atenção para isso foi antes a percepção diferencial dos impactos da presença da Sociologia no ENEM entre as redes de ensino privadas. Assim, vamos abordar, primeiramente, essa divisão interna ao sistema privado de ensino, para, então, avaliar seus impactos nos dois momentos da vida escolar que identificamos.

Perguntamos, entre outros aspectos, se a preparação para o ENEM e os vestibulares está contemplada no Projeto Político Pedagógico da escola em que trabalham; se essas escolas têm projetos específicos para esses objetivos; ou ainda, se há uma cobrança diferenciada sobre a Sociologia em comparação às demais disciplinas, em se tratando de preparação para o ingresso no ensino superior. Das respostas a essas perguntas, uma divisão, já esperada, surge: a preocupação com a aprovação de alunas e alunos nesses exames é diferente entre a rede pública e a privada. Nesta, a aprovação nos exames como um de seus objetivos, ou o objetivo, é muito mais evidente do que 
naquela, quando aparece de modo fragmentado. Ainda que apareça, tal como vimos também na entrevista com a Fatima.

Mas essa não foi a única divisão que veio à tona. As respostas indicam que há uma variação nos objetivos das escolas particulares. Em que pese não haja novidade nessa afirmação, analisar os impactos dessas modulações na prática do ensino de Sociologia pode se mostrar muito frutífero. São essas variações inclusive que nos despertaram para o que estamos chamando de vida escolar "ordinária" e "extraordinária". Isto é, para além de afirmar, simplesmente, que quanto maior a preocupação da escola com a aprovação nos vestibulares e no ENEM, maior será a cobrança sobre professores e professoras, é importante destacar que, mesmo quando essa preocupação não é tão evidente, ela tem efeitos práticos. Não tanto pela presença da Sociologia no ENEM, mas por sua simultaneidade à obrigatoriedade da disciplina no ensino médio.

A Rede de Ensino A tem uma preocupação evidente com a aprovação em concursos, de modo geral, não apenas de ingresso ao nível superior (ENEM, UERJ, IME, ITA), mas também com os exames de ingresso na vida militar. As professoras que lecionam nessa rede (Maria e Mônica), em suas repostas, indicam que a cobrança sobre o/a professor/a de Sociologia é a mesma que a dos demais professores, com relação a atender às expectativas desses exames: "Todo mundo está sendo pressionado. A Sociologia teve que se enquadrar como as outras disciplinas. Não sou livre para escolher nada" (Maria). Por outro lado, esse reconhecimento, segundo uma das professoras the conferiu aumento na carga horária, uma vez que a Sociologia está no ENEM.

Já para o professor da Rede de Ensino B (Ignácio), na qual a aprovação nos exames é apenas um dos objetivos pedagógicos, o impacto sobre a prática de sala de aula é menos evidente e explícita. Ele não indica sofrer uma pressão muito forte para atender a essa expectativa, mesmo que a cobrança sobre os demais professores seja, no máximo, um pouco maior. Porém, essa preocupação não deixa de ser percebida: desde o último ano do ensino fundamental ( $9^{\circ}$ ano), os alunos se dividem em turmas "normais" e "especiais" (estas voltadas para preparar o aluno para os exames). Nestas últimas, algumas das avaliações tomam formato de simulado (não como projeto, mas como avaliação bimestral); a Sociologia está presente na grade curricular de ambas as turmas e nos simulados. Contudo, está de fora dos projetos e nos materiais didáticos voltados 
especificamente para a preparação dos/as estudantes para o ingresso no ensino superior público.

Chama atenção na Rede de Ensino $\mathrm{B}$ a presença da disciplina nas práticas cotidianas e estruturantes da escola, mas a ausência nos projetos. Ao contrário da Rede A, em que a Sociologia se fez, igualmente às demais disciplinas, presente também nas ações diferenciais voltadas para preparação para os exames. Isso nos aponta para uma divisão entre as redes de ensino privada, mas também para dois níveis da vida escolar, a "ordinária" e a "extraordinária".

A incorporação da Sociologia na dinâmica "ordinária" da vida escolar pode ser percebida quando ela está presente nos materiais didáticos, na grade de matérias (ou no aumento do espaço dessa disciplina), nas avaliações e na divisão de turmas "especiais" e nas "normais". É o que chamaríamos de "arraigamento material da Sociologia na estrutura pedagógica das escolas", de modo praticamente automático com a aprovação da Sociologia na grade do ensino médio. E, na medida em que a escola incorpora no seu cotidiano a preocupação com o ENEM, imediatamente, a Sociologia também reflete isso.

A ideia de "arraigamento" é retirada da noção elaborada por David Harvey (2007): "arraigamento material dos processos de acumulação de capital na trama sócioecológica da vida". Ele quer dizer, com isso, que as leis de acumulação de capital não são abstratas e, tampouco, existem apenas como ferramentas analíticas, pois se realizam materialmente (MATIOLLI, 2013); a vida é mercadorizada em seus interstícios e nossas práticas, desde as mais concretas até os modos de sentir, seriam transpassadas por essas lógicas mercadorizantes. O que queremos dizer, ao nos apropriar dessa noção de Harvey, é que a obrigatoriedade da Sociologia na grade curricular do ensino médio faz com que as escolas tenham de incorporá-la em sua estrutura e objetivos, para além da simples contratação do professor. $\mathrm{O}$ que as entrevistas indicaram é que, se os professores da disciplina podem perder liberdade ("somos todos pressionados"), a Sociologia se tornou uma questão inelutável a ser enfrentada pelas escolas em sua prática cotidiana ou "ordinária".

Isso é diferente da incorporação nos projetos especiais ou simulados (distintamente do simulado como avaliação, como no caso da Rede B, mas como exercício e treino para os exames). Quando a escola, como a Rede A, incorpora nos seus 
objetivos a aprovação em concursos, a Sociologia está presente na vida "ordinária" e nos projetos - e professores da disciplina são igualmente "pressionados"; na Rede B, onde não haveria tanto essa preocupação, a Sociologia pode ficar ausente da dinâmica "extraordinária" da vida escolar, assim como os docentes da matéria não participam dos projetos.

A presença da Sociologia no currículo escolar e a circulação de seus professores nos corredores dos colégios, por si só, como efeito da obrigatoriedade de 2008, cria constrangimentos para a não inclusão da disciplina na vida escolar "ordinária" ou mesmo "extraordinária". O professor do Pedro II, quando perguntado se havia projetos especiais na sua escola, diz que seria até constrangedor fazer uma atividade dessas e deixar uma das equipes (a de Sociologia, no caso) de fora.

\section{b) O espaço do professor de sociologia dentro de sala de aula}

Toda essa discussão inicial sobre o papel da preparação para os exames nos objetivos da escola e sobre seus impactos na prática docente de Sociologia no ensino médio tem outros desdobramentos. Um deles, ao qual nos deteremos agora, é o fato de que essas modulações abrem brechas que conferem maior ou menor liberdade ao/à professor/a para ponderar sobre como trabalhar a preparação para o ENEM nas suas aulas.

A preparação para os exames pode ser uma ferramenta de aula possível, e não significar necessariamente apenas a restrição dos objetivos, e conteúdos, a uma lógica utilitarista de educação. As/os professores de Sociologia têm sua própria visão dos objetivos da disciplina. Abstraindo as variações de forma, em geral, todas as respostas do questionário ${ }^{11}$ indicavam a preocupação dos/as entrevistados/as em desenvolver nos/as alunos/as uma visão crítica sobre o mundo de modo que construíssem mediações com a realidade social para além do senso comum. Por outro lado, todos/as também reconheceram a importância da preparação para o ingresso no nível superior, inclusive como uma das responsabilidades da escola. Nas palavras do professor da rede pública estadual (Agostinho): "Penso que seria injusto com eles ignorar completamente essas

\footnotetext{
${ }^{11}$ Respostas à seguinte pergunta: “O que você espera das suas aulas de Sociologia no Ensino Médio?”.
} 
provas e lecionar Sociologia unicamente a partir da minha visão pessoal do que deva ser ensinado e de que forma"

Preparar para a aprovação nos exames pode ser contemplado como um dos objetivos da aula. Por outro lado, essas provas podem ser utilizadas como exercício em sala ou nas avaliações, ou ainda dada questão/tema de redação pode desdobrar em uma discussão que tenha a ver com o conteúdo já estabelecido.

Cabe destacar que esse grau de liberdade depende do nível da cobrança da escola sobre os professores, em um continuum que vai desde a "pressão" exercida pela Rede de ensino A até a "despreocupação" da rede pública. Mas os limites de tal espaço de atuação não são dados apenas pela cobrança para preparação para os exames. Há as limitações do currículo mínimo ou do conteúdo programático em geral (de cada escola ou rede). Quando perguntadas/os sobre a liberdade que têm para preparar aula frente às cobranças das escolas, os/as entrevistados/as falaram que isso seria possível, mas não de modo absoluto, pois têm de responder ao currículo mínimo ou ao conteúdo programático.

A liberdade do professor de Sociologia estaria, então, em conciliar um espaço relativo (limitado pelos currículos e conteúdos programáticos) com suas concepções sobre o que é dar aula dessa disciplina, de modo que, para além da pressão escolar, preparar para o ingresso no nível superior possa ser contemplado por escolha do professor em sua aula.

\section{Considerações finais}

Independentemente da forma como a Sociologia é cobrada no ENEM, e também nos vestibulares, exigindo mais ou menos conhecimento prévio da disciplina, há um imaginário que reconhece essa presença e que tem efeitos práticos, até por acionar circuitos econômicos, como a produção de livros e apostilas. Embora esse imaginário e seus efeitos práticos possam variar dependendo da forma como a Sociologia se apresenta no ENEM, de maneira mais superficial ou mais efetiva em relação ao

conhecimento prévio da disciplina. Sendo, portanto, importante problematizar e compreender essas formas pelas quais é cobrada (FRAGA; MATIOLLI, 2012). Tais efeitos práticos acabam se fazendo sentir também no cotidiano da prática docente, com 
níveis variados, dependendo, entre outras variáveis, da escola investigada. A entrevista com Fatima e, posteriormente, com mais seis professores nos permitiu ter contato com diferentes formas pelas quais esses efeitos podem ser sentidos.

Desse primeiro contato, dois pontos podem ser destacados. O primeiro deles é o de que, no Colégio Pedro II, mesmo antes da obrigatoriedade do ensino de Sociologia, já havia uma preocupação, no discurso e na prática, de essa disciplina contribuir para instrumentalizar os alunos para o ingresso no ensino superior. Mas há diferenças entre esses dois momentos, pois, no atual, com a existência desse imaginário, os esforços de justificação são menores e menos complexos do que anteriormente.

O segundo é o de que os impactos na formatação das aulas e na preparação de provas pela presença da Sociologia no ENEM não são únicos nem homogêneos, sequer em uma rede de escolas como a do Colégio Pedro II. Se surgem diferenças entre unidades da mesma rede, podemos perceber que, para além de uma visão monolítica dessa presença da Sociologia no ENEM resultar em uma mudança nas aulas, nos métodos e nos materiais didáticos, buscando preparar os alunos de maneira consensual para esses exames, o que vai predominar são a diversidade e as tensões.

As seis entrevistas posteriores puderam mostrar que, retomando nossa discussão inicial sobre a tensão entre enquadramento e liberdade, não há um constrangimento entre dois polos herméticos, isto é, ou você prepara para o ENEM ou você forma o cidadão, mas uma gama de possibilidades de conciliação disso pelo professor, e suas crenças, nas quais preparar para o ENEM (usando questões ou temas de redação) pode, no mínimo, ser uma ferramenta para pensar a aula em si ou uma das dimensões possíveis da aula de Sociologia, ainda que não a única. Haveria, então, uma diferença entre a imposição da Rede de Ensino A e a ponderação do professor da rede estadual em entender que a aprovação no exame também tem de existir como possibilidade para seu aluno. Em suma, há liberdade para o professor, mas é preciso qualificar as condições em que ela é exercitada, considerando as gradações que existem entre as escolas e seus efeitos práticos no cotidiano escolar.

Se estamos vivendo sob um imaginário de que a Sociologia ocupa um lugar importante na aprovação dos alunos, no abrir ou fechar das portas do ensino superior, essa questão se coloca, com mais ou menos força, em todas as escolas, privadas ou públicas (estaduais ou federais), podendo alterar a forma como a Sociologia é ensinada, 
provocar uma mudança nos conteúdos e/ou revelar uma divergência entre professores. Portanto, os efeitos heterogêneos dessas avaliações nas diferentes realidades escolares são os reflexos dos ecos de um imaginário que é novo para a própria Sociologia e que, portanto, abre um leque de possibilidades, ainda não totalmente claro, de como lidar com ele, mas que já se faz sentir nas práticas docentes dos professores, conforme relataram nossos entrevistados.

\section{Referências}

ALVES, P. F. P. de A. Almanaque de Sociologia para vestibular e ENEM. Volume Mundo do trabalho. $1^{a}$ ed. São Paulo: OnLine, 2014.

ARAÚJO, S. M. de; BRIDI, M. A; MOTIM, B. L. Sociologia. Manual do Professor. $1^{\text {a }}$ ed. São Paulo: Scipione, 2013.

BOMENY, H; FREIRE-MEDEIROS, B; EMERIQUE, R. B. et al. Tempos modernos, tempos de Sociologia. Manual do Professor. $2^{\mathrm{a}}$ ed. São Paulo: Editora do Brasil, 2013.

CAREGNATO, C. E; CORDEIRO, V. C. Campo científico-acadêmico e a disciplina de Sociologia na escola. Educação \& Realidade, Porto Alegre, v. 39, n. 1, 2014, p. 39-57.

CERRI, L. F. Saberes históricos diante da avaliação do ensino: notas sobre os conteúdos de história nas provas do Exame Nacional do Ensino Médio - ENEM. Revista Brasileira de História. São Paulo, v. 24, nº. 48, 2004, p. 213-231.

FRAGA, A. B; MATIOLLI, T. O. L. A Sociologia no vestibular: o caminho da legitimidade pelo enquadramento. $3^{\circ}$ Encontro Estadual de Ensino de Sociologia. Rio de Janeiro, 28, 29 e 30 de setembro de 2012. Disponível em: $<$ http://www.labes.fe.ufrj.br/> Acesso em: 31 de Maio de 2015.

FRAGA, A. B; MATIOLLI, T. O. L. Sociologia no ENEM: uma análise crítica. Revista Sociologia. São Paulo: Editora Escala. Ano IV, 46ª ed, 2013, p. 12-17.

FRAGA, A. B; MATIOLLI, T. O. L. Os conteúdos de Sociologia nos vestibulares e no ENEM: uma discussão sobre conhecimento prévio. Saberes em perspectiva. Jequié, v. 4, n. 8, 2014a, p. 195-215.

FRAGA, A. B; MATIOLLI, T. O. L. A influência das avaliações externas à escola na prática cotidiana das aulas de Sociologia. $4^{\circ}$ Encontro Estadual de Ensino de Sociologia. Rio de Janeiro, 17, 18 e 19 de outubro de 2014b. Disponível em: $<$ http://www.labes.fe.ufrj.br/> Acesso em: 31 de Maio de 2015.

FRAGA, A. B.; MATIOLLI, T. O. L. A Sociologia na Redação do ENEM. Revista Sociologia. São Paulo: Editora Escala. Ano V, 57 ed, 2015, p. 58-67. 
HANDFAS, A; MAÇAIRA, J. P. O estado da arte da produção científica sobre o ensino de sociologia na educação básica. Revista Brasileira de Informação Bibliográfica em Ciências Sociais - BIB, São Paulo, no 74, 2012, p. 43-59.

HARVEY, D. Notas hacia una teoría del Desarollo Geográfico Desigual. GeoBaires. Cuadernos de Geografia. Apuntes de Geografia y ciencias sociales. UBA-FFyL, 2007.

MACHADO, I. J. de R.; AMORIM, H; BARROS, C. R. de. Sociologia hoje. Manual do Professor. $1^{a}$ ed. São Paulo: Ática, 2013.

MATIOlli, T. O. L. Metáforas da Cidade Partida: a divisão territorial do Rio de Janeiro nas eleições municipais de 2008. Rio de Janeiro: Editora Multifoco, 2013.

MEC. Guia de livros didáticos: PNLD 2012: Sociologia. Brasília: Ministério da Educação, Secretaria de Educação Básica, 2011.

MEC. Guia de livros didáticos: PNLD 2015: Sociologia. Brasília: Ministério da Educação, Secretaria de Educação Básica, 2014.

MORAES, A. C.; TOMAZI, N. D.; GUIMARÃES, E. da F. Orientações Curriculares Nacionais para o Ensino Médio - Conhecimentos de Sociologia. Brasília: MECSEB, 2006.

OLIVEIRA, L. F. de; COSTA, R. C. R. da. Sociologia para jovens do século XXI. Manual do Professor. $3^{\text {a }}$ ed. Rio de Janeiro: Imperial Novo Milênio, 2013.

SILVA, A; LOUREIRO, B; MIRANDA, C. et al. Sociologia em movimento. Manual do Professor. $1^{a}$ ed. São Paulo: Moderna, 2013.

TOMAZI, N. D. Sociologia para o ensino médio. Manual do Professor. $3^{\text {a }}$ edição. São Paulo: Saraiva, 2013. 


\title{
Os impactos da presença da sociologia nos sistemas de ingresso ao ensino superior: o que dizem os professores
}

Resumo: Este trabalho é um desdobramento de pesquisas anteriores, nas quais a preocupação foi analisar as formas pelas quais a Sociologia vinha e vem sendo cobrada nos vestibulares e no ENEM. Corresponde à etapa atual da pesquisa, em que realizamos as primeiras incursões em ambientes escolares com o intuito de entender os efeitos concretos da presença da Sociologia nesses exames na prática cotidiana do ensino da disciplina. Foram entrevistados, no âmbito da cidade do Rio de Janeiro, professores da rede privada e da rede pública de educação básica, em esforço para apreender as maneiras pelas quais a atuação deles em sala de aula foi impactada pelo reconhecimento público de que a Sociologia é cobrada nos sistemas de ingresso ao ensino superior.

Palavras-chave: Ensino de Sociologia; ENEM; Vestibular

\section{The impacts of the presence of sociology on public university entrance exams: what teachers say}

\begin{abstract}
This paper is a outspread from previous researches in which we were concerned to analyze the ways in which sociology was and has been charged in the university entrance exams and in the ENEM. It also corresponds to the current stage of research, where we held the first incursions in school settings in order to understand the specific effects of Sociology presence in these exams in everyday practice of teaching the discipline. Were interviewed within the city of Rio de Janeiro teachers from the private and public high schools, in an effort to grasp the ways in which their performance in the classroom has been affected by the public recognition that sociology is charged in entry systems to higher education.
\end{abstract}

Keywords: Sociology teaching; ENEM; University entrance exams.

Recebido em: 10 de agosto de 2015.

Aceito para publicação em: 24 de julho de 2015 . 